\title{
Approving on the Basis of Moral and Aesthetic Testimony
}

\author{
Daniel Wodak
}

Wei tells you they saw someone do something wrong. Kiara tells you 'Azz Everywhere' is beautiful. Knowing them to be highly reliable, you disapprove of the act and approve of the song.

These are affective responses to normative testimony-in particular, to moral and aesthetic testimony. Much ink has been spilled over whether believing on the basis of such testimony is 'fishy' or 'defective'. Interestingly, both sides in this debate typically accept that approving on the basis of normative testimony is verboten.

We can distinguish stronger and weaker versions of this commitment:

No Reason: Normative testimony gives us no reason for affective responses like approval.

No Justification: Normative testimony does not justify affective responses like approval.

On the first view, you have no reason to approve of the song or disapprove of the act. On the second, you have some reason for these attitudes, but they must be too weak for your responses to be reasonable or justified. We can also distinguish other versions of these views. Some might accept No REASON for aesthetic but not moral testimony, for example.

My main goal is to defend approving on the basis of normative testimony. First, I argue that No REASON is false: once we construct the right comparison cases it is hard to deny that normative testimony gives us some reason for attitudes like approval. Second, I argue that these reasons need not be weak in the way that proponents of No Justification suppose. If an extremely reliable informant says that 'Azz Everywhere' is sublime, this can make approving of it reasonable and justified. 
A subsidiary goal is to show that if approving on the basis of normative testimony is not defective, this matters for broader debates in aesthetics and metaethics. It should make us optimistic that normative testimony gives us (strong) reasons to believe and act while making the 'fishiness' of these responses harder to explain.

\section{Setting the Scene}

So far, this is quite abstract. Some scene-setting is in order.

Let's start with responding to normative testimony. ${ }^{1}$ ''ll follow othersespecially Fletcher (2016) - in focusing on direct deference to pure normative assertions. You directly defer to Wei and Kiara when your responses are based solely upon their testimony (with, perhaps, background knowledge of their reliability: see McGrath 2011: 113; Whiting 2015: 93). This rules out approving of the song after playing it on YouTube. The testimony involves pure normative assertions when you are not told why or in what way the song is beautiful or the act is wrong. This rules out disapproving of the act based on explanatory or descriptive information about its morally relevant features (whether such information is explicit or inferred). ${ }^{2}$ These distinctions aim to isolate what normative testimony alone gives us.

What about approving of the act or song? This is a thin affective attitude that comes in different flavors. We can glom on to it via ostension. If you saw Peter Singer gracefully scoop a drowning child out of a pond, you might morally and aesthetically approve of this act; if the child was saved gracelessly, you might morally approve and aesthetically disapprove.

A few notes about approval. First, it's affective. As in the literature on non-cognitivism, some may worry that 'approval' picks out a (purely)

\footnotetext{
${ }^{1}$ It may well be that not all 'normative' domains generate a prima facie puzzle with deference to normative testimony, as Fletcher notes (2016: 58); I leave that open. My uses of the term 'normative' can be treated as shorthand for 'moral or aesthetic'.

2 Two complications. First, pure normative assertions ascribe thin normative properties: i.e., properties like being good rather than like being graceful. See Roberts (2013) on the distinction. There's a debate about which side being beautiful falls on (see, e.g., Zangwill 2013). I assume that being wrong and being beautiful are thin normative properties; if you disagree, substitute your preferred alternatives. Second, many contend that responding to descriptions of the aesthetically relevant properties of the painting would still be 'fishy', perhaps unlike in the moral case. Hanson (2018: 53-60) challenges this asymmetry. And related issues crop up in relation to 'impure' deference to moral testimony: cf. Hills (2009: 195-6) and McGrath (2011: 137), on the one hand, and Mogenson (2015: 10) and Sliwa (2010: 194), on the other. I only discuss pure normative assertions.
} 
cognitive attitude with normative content (see Rosen 1998: 389). For my purposes, it'd be just as bad if it picked out a (purely) desire-like attitude. What matters for my purposes is that approval has some distinctive phenomenology. I presume that you're familiar with the warm, fuzzy feeling that partly constitutes approval. If you prefer to call it by another name, go ahead.

Second, it's a thin attitude, unlike (say) aesthetic appreciation or moral blame. Some hold the strong view that it is impossible to form such thicker attitudes on the basis of normative testimony-for example, we cannot appreciate an artwork without acquaintance. (For critical discussion, see Whiting 2015: 101 and Hanson 2018: 53-62.) This line of thought is implausible in general. ${ }^{3}$ And I suspect many are drawn to it for bad reasons. Perhaps some conflate whether they would form such attitudes with whether they could do so. I wouldn't hug Sean Hannity, but that doesn't mean I couldn't. Perhaps some think it is impossible to form any attitudes about utterly opaque objects: you just can't loathe ftumch if you have no idea who or what that is. Even if that were true, the objects in question here need not be utterly opaque. Dialectically, you can consider cases where you know plenty about what you (dis)approve of, as long as you are not acquainted with their morally or aesthetically relevant features. In any case, the strong view in question becomes much less plausible with thinner attitudes. Surely there are some affective normative attitudes which are possible to form on the basis of testimony-that's a low bar! I think approval is in this class, which is why I focus on it, but all I need for my purposes is that the class isn't empty.

Third, approval comes in moral and aesthetic flavors. I have no theory about how to demarcate them. There's an equivalent issue for non-cognitivists - see, for example, Björnson and McPherson (2014) with flavors of desire-like normative attitudes. Much of what's said there could carry over.

\section{The Right Comparison Cases}

A major theme of the debate about the 'fishiness' of deferring to normative testimony is that we need to use the right comparison cases. An influential

\footnotetext{
${ }^{3}$ Here's a quick argument against it. Blame's objects include an agent and their action. But we surely need not be acquainted with both objects in order to blame. You can blame opaque agents: I blame plenty of nameless, faceless CEOs for their policies. So why is it impossible to blame known agents when the nature of their wrongful actions is opaque?
} 
way of framing the debate was to compare deference to normative and non-normative testimony. Learning what we morally owe to distant strangers via deference to moral experts seems odd; learning what we legally owe to the IRS via deference to legal experts seems fine (McGrath 2011). But such comparisons may not isolate any fishiness of responding to normative testimony, because they introduce confounding factors. What we morally owe is much more controversial than what we legally owe here, which may explain our intuitions (see Markovits 2012: 306; Sliwa 2012: 186-8).

To avoid such confounding factors, Whiting and Lord have turned to comparing normative deference to normative acquaintance. What's helpful about this approach is that it holds fixed the relevant object of evaluation. For the sake of brevity, I won't describe their key examples, and I'll stick to the aesthetic cases for now and talk about how my points generalize later.

So let's fixate on a comparison between these two examples:

Kiara listens to 'Azz Everywhere' on loop, fixating on Big Freedia's energetic and complex rhythms, the interweaving call-and-response vocal chants, and the clever sampling. Kiara approves of it.

Kiara tells you that 'Azz Everywhere' is a beautiful song. Knowing Kiara to be highly reliable, you approve of it.

We're comparing cases where you and Kiara form identical attitudes with the same object. Whiting and Lord disagree about whether it'd be reasonable to believe that the song is beautiful. But both use such comparisons to pump the intuition that Kiara's testimony gives you no reason at all to approve of the song (Whiting 2015: 96-7, 106-7; Lord 2016, 2018); they argue from such intuitions that we should accept No REAson.

There are two problems with this argument, both of which concern ways in which the intuitions it elicits are not probative. Correcting for these problems elicits probative intuitions that militate against No REASON.

First, comparing cases of acquaintance and deference does not isolate all confounding factors. What we need to use is minimal contrastive pairs.

An analogy may help. How might you test the hypothesis that eating burnt toast causes cancer? A bad approach would be to compare cancer rates among one group who eat burnt toast and another who smoke a pack a day. If burnt-toast-eaters had lower cancer rates, that could be because eating burnt toast is not carcinogenic, or because smoking is more carcinogenic. To isolate the effects of burnt toast consumption, we use minimal contrastive 
pairs: we compare cancer rates among groups who are as similar as possible, except one eats burnt toast.

Similarly, since the goal here is to isolate whether normative testimony gives us reasons for approval, we must avoid confounding factors in comparing deference to acquaintance (burnt toast $v s$. smoking). We need to compare pairs of cases that are as similar as possible except for the presence of normative testimony (burnt toast $v s$. no burnt toast).

How can we generate such minimal contrastive pairs? Consider:

Kiara tells me that 'Azz Everywhere' is a song. Knowing Kiara to be highly reliable, I approve of it.

This is identical to the case of deference above, except for the absence of the normative content in the testimony: the use of 'beautiful'. We can similarly modify other examples of normative deference (including Whiting's and Lord's). This isolates what difference normative testimony alone makes. And once we isolate this, the answer-I contend-is clear as day. Intuitively, I have less reason to approve of 'Azz Everywhere' than you do! If so, then you had some reason to approve of the song. Since the only variable that changes in these comparison cases is the presence/absence of the normative testimony, that must be what made the difference. It gave you some reason to approve. So No REAson is false.

You may have qualms about this argument, but hold them for the moment. They may dissipate when we consider the second problem.

To warm up to it, consider an example from an unrelated contextSchroeder's discussion of undercutting epistemic defeaters:

In a first version of the case, you see Tom Grabit come out of the library, pull a book from beneath his shirt, cackle gleefully, and scurry off. Intuitively, you have a reason to believe that Tom just stole a book from the library. But in a revised version of the case, Tom has an identical twin, Tim, from whom you cannot visually distinguish him. If you're aware of this, then it turns out that you don't have any reason to believe that Tom stole a book after all. Right? Of course that's right. This, after all, is a classic case of an undercutting defeater, and as everyone knows, undercutting defeaters make it the case that things that would otherwise have been reasons for you, instead are not.

This is a natural thought about the case, but your intuitions mislead you. That you still do have some reason to believe that Tom stole a book can be 
observed by comparison with yet a third version of the case. In the third version, Tom and Tim have a third identical sibling, Tam. In this case, you have even less reason to believe that Tom stole a book than in the second, and so in the second it can't have gone away entirely. By similar reasoning, you still have a reason to believe that Tom stole a book even in the third case, because there is a fourth case in which there are four identical siblings and your reason to believe that Tom stole a book is still worse.

(Schroeder 2007: 93)

The upshot of this is that to test whether some fact is a reason for $A$ to $\varphi$ (to believe Tom stole a book) you can't just compare a better case to a worse case (Tom has no twin vs. Tom has one twin); you need to also consider even worse cases (Tom has two twins). How does this apply to our discussion? As many have noted, normative acquaintance may be generally better than deference to normative testimony without the latter being 'defective' or 'fishy' (Driver 2006: 625-9; Sliwa 2012: 193-4). So we shouldn't just compare acquaintance (no twin) to deference (one twin) and declare that in the latter case there's no reason to approve. We must compare cases of deference (one twin) to relevantly similar but worse cases (two twins, three twins, etc.).

What would a similar but worse case be? Imagine that instead of hearing from Kiara that 'Azz Everywhere' is beautiful, you heard this from Timon, whom you know is less reliable on such matters. Intuitively, you'd have less reason to approve of the song based on Timon's testimony. So you must have some reason to approve based on Kiara's testimony. We can construct a sequence of cases with informants of gradually decreasing reliability (Timon, Pumbaa,...). In each, there's less reason for you to approve. Since a trademark feature of reasons is that they are gradable-they count in favor of actions or attitudes to different degrees-this is evidence that the normative testimony gives you reasons for attitudes like approval. ${ }^{4}$

\section{From Some Reason to Strong Reasons}

In embracing No REASON, Whiting and Lord may have taken on an unnecessarily strong commitment. Whiting commits to No ReAson to support the conclusion that aesthetic testimony cannot give you knowledge

\footnotetext{
4 A central argument from Maguire (2017) is that there are no reasons for attitudes because the considerations that favor attitudes are not gradable. I've shown the opposite. The considerations that favor approval in these cases are gradable, so they're reasons.
} 
of the aesthetic properties of artworks. The weaker view that aesthetic testimony does not justify approval may suffice for that purpose. And that view, No Justification, may seem unscathed by the argument so far. ${ }^{5}$

In this section I'll offer two arguments for the view that if we reject No Reason, we should reject No Justification. The first is quick: No Reason has a clearer theoretical rationale. Consider the acquaintance principles that are widely endorsed in aesthetics. It's one thing to hold, as Lord does, that only acquaintance can allow you to possess reasons for responses like approval; normative deference cannot give you any reason for those attitudes. It's another to hold that deference to normative testimony can also play the same role as acquaintance, but can only play it a little bit. Why can deference to testimony get your foot in the door, but not push it wide open? Why would this separate source of normative support be barred from making affective attitudes reasonable, justified, or fitting? Denying No REAson while accepting No Justification seems ad hoc.

The second argument is more complex. It uses the verdicts from previous examples as the thin end of the wedge. Earlier, we saw that you must have some reason to approve of the song when Kiara says it's beautiful, given the comparison to worse versions of this case. Now we generate better versions of the case. We can increase the reliability of the testifier: intuitively, you have more reason to approve when you get such testimony from an extremely reliable expert. We can also up the ante in the content of the testimony: if hearing that a song is beautiful gives you some reason to approve of it, hearing that it is sublime gives you more reason to do so.

We can also do both at once. Imagine an extremely reliable informantNala, perhaps-says 'Azz Everywhere' is transcendent, breathtaking, superlative. So you approve of it. There's much more reason to do so in this case than when you approve based on Kiara's (or Timon's) word alone. ${ }^{6}$

Indeed, I contend that you have much stronger reasons to approve of the song solely on the basis of Nala's testimony than you would have in

${ }^{5}$ You may even think No Justification is suggested by the argument so far. Consider Schroeder's (2007: 93) explanation of what goes wrong in our intuitions about Tom Grabit's thievery. Take the claim that there is reason to believe Tom stole a book. Asserting that claim would implicate that there is a good reason to believe Tom stole a book. That implicature is false if Tom has an identical twin. Schroeder argues that the claim is true, but we intuit that it is false due to this infelicity. More generally, we sometimes misleadingly intuit that there is no reason to $\varphi$ when the only reasons to $\varphi$ are weak. If we've misleadingly intuited that there's no reason to approve on the basis of normative testimony, you may think the only reasons to do so must also be weak. This, however, would be a mistake. Schroeder's Gricean story isn't the only way of explaining why we form misleading intuitions about existential claims about reasons.

${ }^{6}$ A helpful referee notes that we can also increase the number of testifiers. If we imagine the same testimony from a group of Nalas, the point is even stronger. 
ordinary cases of aesthetic acquaintance. Philosophical descriptions of acquaintance rarely sound ordinary. Lord, for example, describes an agent's acquaintance with an artwork, Nefertiti's Bust, as follows: 'She studies its features for an hour. She not only passively looks at the bust, but also actively thinks about how the various features of the bust interact.' How many artworks that you admire in a trip to a museum do you study for an hour? One reason I've used a staple of New Orleans bounce music-aside from thinking that aesthetics needn't be so preoccupied with displaying hushed reverence for high-brow art-is that it's harder to over-intellectualize acquaintance in such cases. I'm acquainted with songs I heard once, for a few minutes, while chatting to friends and thinking about lunch. If approval of art can be justified on that basis-and it surely can-then surely it can be justified on the basis of testimony from experts.

\section{Generalizing}

I've argued against No ReAson and No Justification. Before we consider an important objection, I want to highlight a feature of the method I've used. It offers a recipe for generating counterexamples to claims like No REASON and No Justification. We can fill in the details in different ways.

I've generated comparison cases using aesthetic attitudes towards particular artworks. We can also consider aesthetic attitudes towards groups or genres of artworks: Kiara can tell you about the beauty of (a) 'Azz Everywhere', (b) Big Freedia's oeuvre, or (c) New Orleans bounce music. Substituting in groups or genres to the comparison cases above may elicit stronger intuitions against No Reason and No Justification. (It also further complicates the view that we cannot form such attitudes without acquaintance. What does acquaintance with a genre involve?)

We can also generate comparison cases using moral testimony. (Notably, Lord 2018 compares acquaintance to deference in arguing that moral testimony gives us no reasons for affective attitudes.) Start with:

Wei's case: Wei tells you that they saw someone do something wrong. Knowing Wei to be highly reliable, you disapprove of the act.

Now compare:

Xiao's case: Xiao says they saw someone do something. Knowing Xiao to be highly reliable, you disapprove of the act. 
Ying's case: Ying says they saw someone do something wrong. Knowing Ying to be fairly reliable, you disapprove of the act.

Wei's case and Xiao's case provide minimal contrastive pairs: they are identical but for the presence of the moral testimony ('wrong'). You have less reason to disapprove in the latter than the former. Wei's case and Ying's case differ only in the reliability of the informant. You have less reason to disapprove of the act in Ying's case, since Ying is less reliable. So you must have some reason to disapprove on the basis of Wei's word.

If this is right, we're now under pressure to grant that moral testimony can make affective responses like disapproval justified. Consider cases like:

Zhao's case: Zhao says they saw someone do something evil, monstrous, reprehensible. Knowing Xiao to be extremely reliable, you disapprove of the act.

Intuitively, you have very strong reasons to disapprove on the basis of Zhao's word. This is plausible when we compare Zhao's case to Wei's. But it is also plausible when we consider Zhao's case to ordinary moral acquaintance. When you witness an act of wrongdoing, I doubt that you often 'study its features for an hour,... actively thinking about how the various features of the [action] interact'. Ordinary disapproval of misdeeds isn't so effortful or intellectualized. If disapproval in cases of ordinary acquaintance is justified-and it surely is - then so is disapproval based on such extremely reliable moral testimony.

These cases all involve moral disapproval of act-tokens. But we can also use act-types, like doxing (finding and publishing identifying information about particular individuals online). I'll describe some such cases below. That this recipe of generating can be filled in with different details is important: it gives us a balanced, diverse diet of cases.

\section{Overgeneralizing?}

But does the argumentative strategy overgeneralize? Compare these cases:

Scar tells Shenzi a hilarious joke. Shenzi laughs.

Shenzi tells Banzai that Scar said something funny. Banzai laughs.

Banzai tells Ed that Scar said something. Ed laughs. 
While Shenzi's laughter is a reasonable response to a good joke, Banzai's laughter is not a reasonable response to the bare report that a good joke was told. You might think that my approach delivers the wrong result about this case. Why? Because we can still compare Banzai to Ed. ${ }^{7}$

If my insistence upon using minimal contrastive pairs forced us to accept such verdicts, that'd be a problem. But it doesn't. My approach is an intuition pump: it's not enough that we can compare Banzai to Ed; the comparison must elicit the intuition that Ed has less reason to laugh than Banzai. And to my mind, it does no such thing. ${ }^{8}$ So the method doesn't trivially over-generate reasons. Reflecting on such cases should make us more confident about the probity of the intuitions it elicits above, and more willing to take them at face value rather than explain them away.

Is this a strategic misstep? If the method I've used doesn't force us to accept that wherever there are minimal contrastive pairs there are also reasons, can't my opponents just say that they don't share my intuitions? Can't they say that it doesn't seem that there's less reason to approve of 'Azz Everywhere' based on testimony that it's a song than based on testimony that it's a beautiful song?

Sure. They can say that such cases are like Ed's and Banzai's laughter. Likewise, Schroeder's opponents can say that you have no less reason to believe that Tom stole a book when Tom has two identical twins rather than one. Biting the bullet is a possible response to any argument from intuitions in philosophy. But that doesn't mean it's a good response here.

Moreover, while I described my approach as involving a recipe for generating counterexamples, it's more apt to say that I've offered two recipes: using minimal contrastive pairs; and comparing better and worse versions of testimonial cases (Kiara $v s$. Timon; Kiara $v s$. Nala). Recognizing this matters, as it gives my opponent more bullets to bite.

\section{Unreasonable or Irrational?}

A more promising way to object to my argumentative strategy is to explain away the relevant intuitions. I'll focus on two strategies for pushing this objection, focusing on the moral testimony cases.

\footnotetext{
7 Thanks to Rachel Achs, David Enoch, Keshav Singh, and a few others for offering versions of this objection (p.c.).

${ }^{8}$ The second possibility considered in Section 6 may account for any intuitions we have about the differences between Banzai's and Ed's laughter in response to testimony.
} 
The first appeals to the distinction between reasons for and reasons against. It's worse to kill someone painfully than to kill someone painlessly, but not because there's more reason for killing painlessly; there's just more reason against killing painfully. Likewise, one might say: disapproving on the basis of Xiao's or Ying's testimony is worse than disapproving on the basis of Wei's, but not because there's more reason for disapproving on the basis of Wei's word; there's just more reason against disapproving in the other cases.

To motivate this, note that there are cases where there's more reason against one response to testimony even though there's no reason for another, for example:

Weaker and Stronger Response: I tell Adele and Belle that the Mona Lisa is in France. This prompts Adele to believe that it's in Germany and Belle to believe that it's in Berlin.

Unreliable and More Unreliable Testifier: Adele tries to predict who will win the next election by asking me, even though they're in a position to know that my answer is based on the flip of a coin. Belle tries to predict who will win the next election by reading propaganda, even though they're in a position to know it is inaccurate most of the time.

In both cases there's more reason against Belle's belief than Adele's, but no reason for Adele's beliefs about the painting or the election. So, why not say the same in my cases of disapproving on the basis of normative testimony?

Three responses. First, there are explanations for why there's more reason against Belle's belief even though there's no reason for Adele's. And the explanations do not carry over to the cases of disapproving on the basis of normative testimony. In Weaker and Stronger Response, it's epistemically worse to believe something stronger than something weaker on the basis of no evidence. Belle's belief is stronger in the familiar sense that Belle's belief entails Adele's but not vice versa. ${ }^{9}$ Neither has any evidence for their belief. That's why there's more reason against Belle's belief even though there's no reason for Adele's belief. This can't apply to our cases. You form the exact same response when you defer to Wei, Ying, Xiao, and Zhao; if the response is the same, it can't be weaker or stronger. What about Unreliable and More Unreliable Testifier? Here there's no reason to believe on the basis of

${ }^{9}$ For helpful discussion of this issue, I'd like to thank Selim Berker and Jan Dowell. 
evidence that you're in a position to know has a .5 chance of being accurate, but there's more reason against believing on the basis of evidence that you're in a position to know is inaccurate. This doesn't apply to our cases either. In each of the four cases you respond to a reliable informant; and in two of those cases-Wei and Ying's-we hold the reliability of the informant fixed.

The upshot is that the objector needs to explain why there's more reason against disapproving in Xiao's or Ying's case. (And explain this without presupposing that there are reasons for disapproving in Wei's case.) ${ }^{10}$ The onus is on the objector to do this. Color me skeptical.

Second, for this to explain away our intuitions, we must be conflating less reason for and more reason against. Is this plausible? We don't conflate the two in cases like Adele's and Belle's: it's not intuitive that there's less reason for Belle's response than Adele's; instead, it's intuitive that Belle's response is more unreasonable than Adele's. Plus, you'd expect that when this hypothesis is raised, we'd cease to conflate the two. I don't find this: it doesn't become intuitive that your response is more unreasonable in cases like Ying's.

Third, the objector needs to explain our intuitions not only about cases like Xiao's and Ying's (which are intuitively worse than Wei's), but about cases like Zhao's (which is intuitively better than Wei's). Why is it intuitive that you have more reason to disapprove on the basis of Zhao's testimony if you have no reason at all to do so? The appeal to reasons against doesn't seem well placed to explain this.

The second strategy aims to explain away our intuitions by appealing to the distinction between rationality and reasonableness: ${ }^{11}$ the former is a relation of coherence between attitudes; the latter is a relation between attitudes and facts that favor them. If an assassin intends to kill a target quietly, it is less rational to shoot the target with a loud AR-15 than with a silenced sniper rifle; but it's not less reasonable to shoot the target with an AR-15. The hypothesis here is that we misleadingly intuit that there's less

10 You might think Hopkins' view fits the bill here. Hopkins' 'Unusability Pessimism' holds that there's a duty not to form moral or aesthetic beliefs without grasping the 'grounds' or reasons for those beliefs (Hopkins 2011, 2017). If you violate this duty in Xiao's or Ying's case, plausibly there's reason against your disapproving in those cases. But that's not enough. Why is there more reason against your disapproving in those cases? The natural answer seems to be: you are grasping some reasons for your responses in Wei's case. So I'm not sure that this view fits the bill. As Hills (2009: 98, fn. 8) notes, their view is 'an elaboration' of Hopkins' view; I discuss this view in more detail in Section 7.2.

${ }^{11}$ The distinction here is familiar (e.g., see Kolody 2005), but the relations are often somewhat confusingly labeled 'structural rationality' and 'substantive rationality'. 
reason to defer to Xiao than Wei when in fact it's just less rational to defer to Xiao than Wei.

This strategy also faces problems. First, we're owed an explanation for why it is less rational-less coherent-to defer in Xiao's case than in Wei's. And for this explanation to cover all of the cases, it'd need to extend to the other comparisons: Wei's vs. Ying's; Wei's case vs. Zhao's. The last of those comparisons is especially tricky. Moreover, a general obstacle for explaining these data is that in each case you form the exact same response: you disapprove of the same action. Why would the exact same attitude cohere better or worse with your other attitudes, when those are held fixed?

Say the objector offers such an explanation. Here's a second problem. That explanation will ultimately appeal to contingent features of the casethe presence of some other attitude that, coupled with the approval, generates incoherence. But we can factor this feature into how we construct the case. For example, say the objector posits that you have a background disposition to morally disapprove of actions iff you have some evidence that they're immoral. This disposition coheres well with your disapproving of an action solely based on hearing Wei say they 'saw someone do something wrong'. But the disposition does not cohere well with your disapproving of an action solely based on hearing Ying say that they 'saw someone do something'. This seems to explain this comparison (though not the others). Now let's imagine someone with different background attitudes: for example, someone who believes-contrary to reason-that every action is wrong. For this person, disapproving of an action based on Wei's or Ying's testimony would be equally coherent. It is still intuitive that this person has less reason to disapprove on the basis of Ying's testimony than Wei's. We can make similar moves for any other way of generating incoherence. Which makes it hard to believe our intuitions track coherence rather than reasonableness.

Third, this objection generates implausible predictions. Consider Skeptic. They believe that if a reliable informant says that $p$, that's never a good basis to believe $p$. (Grant that such skepticism is false and contrary to reason.) Like many proponents of revisionary philosophical views, Skeptic might find it hard to live up to their scruples. They might hear reliable testimony that $p$ and come to believe $p$. Now compare Skeptic's response to expert testimony to my response to some punter like Ying. It's less rational for Skeptic to defer to an expert than for me to defer to Ying. (Since I think it's kosher to defer, so my deference isn't incoherent; but Skeptic's is.) The view that we're conflating what's reasonable with what's rational predicts that we'll find it 
intuitive that it's less reasonable for Skeptic to defer to experts than for me to defer to Ying. But this isn't intuitive at all. The expert is far more reliable than Ying. So intuitively, the Skeptic has more reason, not less, to defer. So we do not seem to be conflating reasonableness with rationality.

These responses may not be conclusive. But all I'm aiming to do is throw down a gauntlet for my opponents. If you insist that normative testimony gives us no reason to approve, provide a better explanation of the data.

\section{From Approval to Belief and Action}

Now we get to my subsidiary aim: showing that if normative testimony gives us (strong) reasons to approve, we should be optimistic that it also gives us (strong) reasons to believe and act. I'll now show why this is so by exploring how the argumentative strategy generalizes. For any thesis like No REASON and No Justification, we can and should test them using the right comparison cases, and once we do so we elicit probative intuitions in favor of optimistic views about the power of normative testimony.

\subsection{Epistemic Reasons and Knowledge}

Let's start with pessimistic views about reasons for belief. There are, once again, stronger and weaker versions of such views:

No Epistemic Reason: Normative testimony that $p$ cannot give us any epistemic reason to believe $p$.

No KnOwledge: Normative testimony cannot transmit knowledge that $p$.

We could further distinguish between such varieties of pessimism. Many, for example, allow for exceptions in a narrow range of rare cases; ${ }^{12}$ some endorse pessimism about aesthetics but not about morality. ${ }^{13}$ I'll set such variations on these theses aside for expository convenience.

\footnotetext{
12 In the aesthetics literature, the exceptions are meant to include lost artworks, past performances, and common knowledge (see Robson 2012: 5, and references therein). We could also treat deference to experts in emergencies as an exception to pessimistic views about moral testimony (see, e.g., Mogenson 2015: 3). Note that my argument applies even when no such exceptional circumstance obtains, so it is a genuine threat to pessimism.

13 See, e.g., Pettit $(1983,2008)$.
} 
We can generate the right comparison cases using our familiar recipe(s):

Amare's case: Amare tells you that doxing is an immoral practice. Knowing that Amare is highly reliable, you believe that doxing is an immoral online practice.

Barak's case: As above, except Barak tells you that doxing is a practice.

Camilla's case: As in Amare's case, except Camilla is fairly reliable.

Daquan's case: As in Amare's case, except Daquan is extremely reliable and says doxing is reprehensible, not just immoral.

Intuitively, these changes make a difference: when we remove the normative content from the testimony or reduce the reliability of the informant, you have less reason to believe that doxing is immoral. When we increase the reliability of the informant and up the ante in the content of the testimony, you get more reason to form that same belief. This is a problem for No EPISTEMic ReAson.

You may think: So what? Perhaps proponents of pessimistic views have only ever been sympathetic to No Knowledge, not No Epistemic Reason.

Two responses. First, many proffered views are ambiguous between No Epistemic Reason and No Knowledge. ${ }^{14}$ Wollheim defined the 'Acquaintance Principle' as follows: 'judgements of aesthetic value, unlike judgements of moral knowledge, must be based on first-hand experience of their objects and are not, except within very narrow limits, transmissible from one person to another' (1980: 233). We don't literally transmit judgments when we give people testimony. At most we transmit normative support for those judgments. Wollheim's language suggests that the principle precludes the transmission of knowledge (given the comparison to moral knowledge). But does it allow the transmission of reasons? It's unclear. A similar ambiguity is present in a recent discussion from Hanson:

By and large, independently of whether they are evaluative realists or antirealists, most people accept that evaluative judgments of an object should be responsive to certain nonevaluative features of that object. Without

\footnotetext{
${ }^{14}$ It is rare for both claims to be discussed, and hence hard to find clear cases where the former is denied but the latter is accepted. An exception is Groll and Decker, who consider-but do not ultimately endorse-the view that 'while testimony can give epistemic reasons for moral belief, it can never give the sort (or level) of justification that is required for propositional moral knowledge' (2014: 56, emphasis theirs).
} 
being aware of certain details of what Betty did, you're not in a position to judge that what Betty did was wrong. Similarly, without any awareness of what Ryoanji looks like, you're not in a position to judge that it is beautiful. Call this the minimal epistemic requirement (MER).

(Hanson 2018: 55, footnote omitted) $^{15}$

If your judgment that doxing is immoral is not based on the nonevaluative features of doxing, you've violated MER. But what does that entail? If you're 'not in a position to judge', do you lack any epistemic reason for that judgment, or does the judgment merely fall shy of knowledge? Is the thesis that 'most people accept' No Epistemic Reason or No KNOWLEDGE?

Second, and more substantively, denying No Epistemic Reason puts pressure on a commitment to No KNowledge. The reasons why this is so mirror the points made earlier in relation to similar weaker and stronger claims about approving based on normative testimony. For one, No Epistemic Reason is a more principled position than No KNOWLEDGE. If testimony can transmit some degree of epistemic justification, why can't it transmit enough to generate knowledge? If our evaluative judgments must be responsive to the non-evaluative features of their objects, why is there anything to be said, epistemically, in favor of testimonial beliefs that flagrantly violate this requirement? In other words, we're owed a theoretical rationale for the view that deference to testimony can play the same epistemic role as acquaintance, but can only ever play it a little bit. ${ }^{16}$

For another, the comparison between cases like Amare's and Daquan's raises problems. If you have some epistemic reason to believe that doxing is immoral in Amare's case, you have much stronger reasons when an expert says it's reprehensible. So why can't you get to strong enough reasons to suffice for moral knowledge? If this is right, then we should be skeptical of both the weaker and the stronger forms of pessimism.

\footnotetext{
15 The omitted footnote is important, as there Hanson notes that 'a possible exception to this might be judgments formed on the basis of testimony, but this is highly contentious'. Later, in discussions of the Acquaintance Principle, they seem to rely on a version of MER that does not include any exception for testimonial aesthetic knowledge (Hanson 2018: 62).

${ }^{16}$ Of course, knowledge may require more than true belief that is sufficiently supported by epistemic reasons, but it's not like your beliefs in cases like Daquan's are always Gettiered. So we still need a rationale for why they can't ever amount to knowledge.
} 
Similar points apply to believing based on aesthetic testimony. Which is important, since it threatens views that are so widely entrenched that Meskin recently described them as a 'Neo-Kantian orthodoxy' (2004: 72). ${ }^{17}$

There is one final implication for pessimism about believing or judging on the basis of normative testimony. As Robson (2012) notes, such 'pessimism is more often assumed than argued for'. Whiting (2016) argues for the conclusion that we cannot gain aesthetic knowledge from testimony via arguing that it cannot 'rationalize' affective attitudes like approval. If aesthetic testimony can 'rationalize' affective attitudes like approval, proponents of pessimism have ever fewer arguments for their view.

\subsection{Moral Reasons for Action}

The view that aesthetic testimony cannot transmit aesthetic knowledge is more common than its moral counterpart. By contrast, the view that moral testimony cannot give you moral reasons for action is more common than its aesthetic counterpart. Once again, we can disambiguate stronger and weaker versions of this commitment.

No Moral Reason: Testimony that $\varphi$ ing is morally right cannot provide any moral reason to $\varphi$.

Not Praiseworthy: Testimony that $\varphi$ ing is morally right cannot provide sufficient moral reason to make it praiseworthy to $\varphi$.

To illustrate the difference, imagine you tell me ' $\varphi$ ing is morally right'. Knowing you to be a reliable and virtuous person, I $\varphi$. The first view says that there was no moral reason for me to do so-where moral reasons are the 'the right kind' of reasons to make my act morally praiseworthy. The second says your testimony only gave me a weak moral reason to $\varphi$.

Interestingly, many metaethicists have explicitly endorsed the stronger view, No Moral Reason. Many metaethicists are committed to the view that moral reasons are 'right-makers': the moral reasons to $\varphi$ are the facts in virtue of which $\varphi$ ing is morally right. ${ }^{18}$ Your testimony itself does not make

\footnotetext{
17 Arguably, the neo-Kantian orthodoxy concerns a doxastic and affective state, not a purely doxastic one (Lord 2018, Gorodeisky 2010). But I don't know how much this matters; my argument can target doxastic and affective states.

${ }_{18}$ Note the connection between this view and the 'minimal epistemic requirement' that Hanson said 'most people accept': if 'evaluative judgments of an object should be responsive to
} 
$\varphi$ ing morally right, or give me access to any facts that make $\varphi$ ing morally right. So it follows that it does not give me any moral reason at all to $\varphi$. As Markovits explains this common view: 'The problem with moral deference ... is that morally deferential agents can't act for right-making reasons', and moral reasons are right-making reasons (2012: 304). ${ }^{19}$

The most prominent proponents of this view are Alison Hills and Sarah McGrath. Here's a key passage where McGrath endorses it:

$[\mathrm{M}]$ oral deference does not put one in a position to do the right thing for the right reasons even in those cases in which it delivers genuine moral knowledge. If the child refrains from lying on a given occasion because he knows that lying is wrong but has no grasp on why it is, then his refraining from lying on that occasion is not based on the reasons that there are not to lie. (McGrath 2011: 133, emphasis added)

Similarly, in a range of cases where an agent $\varphi$ s on the basis of testimony that $\varphi$ ing was the right thing to do, Hills says: 'She is responding to testimony, not to moral reasons' $(2009: 111,116)$. Moral testimony does not give us any moral reasons to act, as those reasons are 'the features of actions that determine whether those actions are right or not' (2009: 112).

The commitment to No Moral Reason is also meant to be plausible independently of a commitment to No KNowledge. As McGrath said in the quote above, when we act on the basis of moral testimony we don't act for moral reasons even when we act on 'genuine moral knowledge'. Similarly, Nickels (2001: 259) holds that 'all that moral testimony provides is a correct moral belief without understanding', and in particular 'it does not provide a basis for morally good action'. (It's not clear here whether

certain nonevaluative features of that object', presumably they must be responsive to the features in virtue of which that object has its evaluative properties.

${ }^{19}$ A related commitment shows up in many discussions of 'the Puzzle of Normative Testimony'. One description of that puzzle is that 'each of these four theses has considerable prima facie plausibility, but together they entail a contradiction':

(1) When an agent A performs an action $\Phi$ in circumstances $C$, and his so $\Phi$-ing is entirely on the basis of the fact that his virtuous and reliable friend told him that he ought to $\Phi$ in $\mathrm{C}$, A thereby $\Phi$-s in $\mathrm{C}$ for good reason.

(2) If someone $\Phi$-s in C entirely on the basis of some fact F, F is thereby A's only reason for $\Phi$-ing in C.

(3) The fact that a virtuous and reliable friend has told one that one ought to $\Phi$ in $\mathrm{C}$ is not itself a good reason to $\Phi$ in $\mathrm{C}$-rather, the good reason(s) is (are) the practical reasons on which the virtuous and reliable friend's testimony is based.

(4) If someone's only reason for $\Phi$-ing in C is not a good reason to $\Phi$ in $C$, then $A$ does not $\Phi$ in C for good reason (McKeever and Ridge 2012: 110-11, emphasis mine). 
lacking 'a basis for morally good action' means lacking any moral reason whatsoever.) However, we can use the recipe(s) I've offered to challenge the view in the exact same way we challenged its doxastic counterpart. Consider:

Pablo's case: A spy infiltrates a villain's lab. Their highly reliable informant, Pablo, left them a message: 'There's a big red button in the next room. It'll be hard to push it, but morally you must do so.' The spy manages to push the big red button, saving the day.

I already find it intuitive that the spy had some moral reason to push the button, and is morally praiseworthy, even when we stipulate that they were acting solely on the basis of Pablo's (accurate) testimony. But such intuitions are bolstered once we generate the right comparison cases:

Quentin's case: As before, except the informant, Quentin, left this message: 'There's a big red button in the next room. It'll be hard to push it.'

Rae's case: As in Pablo's case, except the informant, Rae, is only fairly reliable.

Sami's case: As in Pablo's case, except the informant, Sami, is extremely reliable.

In each case, the spy does what morality requires. Intuitively, they had less moral reason to do so when the moral content of the testimony was stripped away (Quentin's case) or the informant was less reliable (Rae's case); and they had more moral reason to do so when the informant was more reliable (Sami's case). So moral testimony must give us some moral reasons to act; and plausibly, it sometimes gives us strong moral reasons, meriting praise.

This is a novel argument against Hills and McGrath's views. And it has a broader upshot. Their view, recall, was that deferential agents do not act for 'moral reasons' because they do not act for 'right-making reasons' and moral reasons are right-making reasons. This conjunction must be false. If deferential agents do act for moral reasons, then either deferential agents act for right-making reasons, ${ }^{20}$ or moral reasons need not be right-makers. ${ }^{21}$

\footnotetext{
${ }^{20}$ This is Markovits' view: 'it is subjective reasons that are relevant to the assessment of an action's (or an agent's) moral worth', and when moral testimony gives us moral knowledge, that 'testimony is the reason we ought to perform that act'. So 'the deferential agent may.... act for right-making reasons after all' (2012: 306-7, emphasis original).

${ }_{21}$ See Johnson-King (2019) among others. See also Wodak (2020) for an argument for the view that not all moral reasons can be right-makers.
} 
Of course, the conclusion that moral testimony can give us strong moral reasons to act is consistent with the view that acting on those reasons falls shy of some moral ideal. Perhaps it does not give us maximal moral worth. (Some of McGrath's remarks suggest sympathy for such a view. ${ }^{22}$ ) But even if this is right, as Sliwa (2010: 193) notes, it 'does not show that the obstacle to moral worth is moral testimony', rather than 'the agent's moral ignorance'. Acting with knowledge of right-making reasons may be better, without that showing anything defective about acting on moral testimony. ${ }^{23}$ Indeed, nothing in this chapter is meant to suggest that approving, believing, or acting on the basis of normative testimony meets every normative ideal. 'Azz Everywhere' does not meet every ideal either. It's still a great song. I just don't see what's puzzling about deference falling shy of perfection.

\section{Conclusion}

Normative testimony gives us some reason, and sometimes strong reasons, for affective attitudes like approval. And if this is right, we should be optimistic that aesthetic and moral testimony can give us reasons to believe and act, and these reasons can be sufficient for knowledge and moral worth.

These are the conclusions I've argued for. But in some moods, I'm equally attached to the methodological point that the right way to test such commitments is to use comparisons to minimal contrastive pairs and better and worse versions of cases of deference to normative testimony.

I want to close, however, by noting that if I'm right that normative testimony gives us reasons for attitudes like approval, this makes it harder to explain the 'fishiness' of believing or acting based on such testimony. To see why, consider a prominent, promising explanation of the 'fishiness' of deference to normative testimony from Enoch (2014) and Fletcher (2016).

Enoch claims that 'to explain the fishiness of moral deference' we should appeal to 'plausible connections between the making of moral judgments

\footnotetext{
${ }^{22}$ If someone $\varphi s$ because they have testimonial knowledge that it is the right thing to do, 'this detracts from the status of [their] action', but they could 'deserve praise' even though they 'fall ... short of an important ideal associated with moral agency: that of doing the right thing for the reasons that make it right' (McGrath 2011: 132, 135, emphasis original).

${ }^{23}$ Hence, nothing I've said targets a thesis we can call Not IdEAL: Affective responses like approval based on normative testimony are always worse than the best cases of such responses based on acquaintance. (We do need 'the best' to make this thesis plausible, though, in light of comparisons between the ordinary acquaintance and Oracle cases above.)
} 
and certain emotional responses' (2014: 26). Say you get testimony that a war is morally wrong. Enoch says it would be fishy to come to believe that the war is wrong and not form certain emotions: there is something atypical or odd-'cold', 'too intellectual' - about judging that the war is morally wrong without corresponding emotions like disapproval. What if you judged that the war is wrong and formed those emotions? Enoch says that to 'respond emotionally to the war's wrongness de dicto ... is sufficiently atypical to be odd' (2014: 29-30): 'Typically, the emotional responses that are closely connected with moral judgments are responses to the morally wrong (say) de re, and not merely de dicto, that is, under the description "morally wrong"' (2014: 28). So either way, your deference is fishy.

This explanation is generalized to deference to aesthetic testimony:

[I]f having formed the comparative aesthetic judgment by deferring to an expert, I then proceed to emphatically assert how much greater Mozart is than Bach, ... and so on, this would be odd at the very least. And the oddity may be explained by the fact that the relevant emotional responsestypically, to the beautiful de re, not merely de dicto-are absent here.

(Enoch 2014: 30)

Fletcher's view differs from Enoch's in important ways, but the underlying explanation of the fishiness of deference to normative testimony is similar. Moral 'sentiments are at least difficult to form on the basis of pure, direct, testimony', and given plausible connections between making moral judgments and forming certain emotional responses, this explains the fishiness of deferential moral beliefs (in a way that's friendly to realism):

[I]n cases of pure, direct moral deference the receiver is told that someone performed some wrong action but is given no further details. In such a case, unless the receiver enriches the content of the testimony, they will have insufficient information to form the appropriate sentiments towards the agent or their action. This is because moral sentiments are responses that we have to the properties of the relevant action or agent (etc.). Without proper acquaintance with them the attitudes are very unlikely to arise even if we know that they would, were we so acquainted. [So] in cases of such deference the problem stems from the receiver coming to form the judgment that negative moral sentiments are fitting whilst probably lacking such attitudes. (Fletcher 2016: 65) 
Fletcher holds that this explanation generalizes to other problematic cases of normative deference, like aesthetic and prudential deference (2016: 68).

I used to find this explanation satisfying. But if normative testimony gives us reasons for emotions like approval, the explanation is at best incomplete. To see why, let's walk through it step by step, holding fixed the relevant normative proposition-the war is wrong; Mozart is better than Bach (!):

(1) It is odd to believe $p$ in response to testimony that $p$.

(2) But testimony that $p$ provides good epistemic reason to believe $p$.

(3) It is odd to believe $p$ without (e.g.) approving of $x$.

(4) It is odd to (e.g.) approve of $x$ in response to testimony that $p$.

There's an initial tension between (1) and (2): Why is it fishy for you to respond to reasons to believe $p$ by believing $p$ ? The solution is meant to come from (3) and (4): it is odd to form the beliefs without certain emotions, and odd to form those emotions on the basis of the normative testimony, so it is odd to form normative beliefs on the basis of the normative testimony.

Now note that if my arguments are right, we should also accept:

(5) Testimony that $p$ provides good reason to (e.g.) approve of $x$.

The same tension now reemerges between (4) and (5). If we needed to explain why it's fishy to respond to reasons to believe $p$ by believing $p-$ the tension between (1) and (2) - we need to explain why it's fishy to respond to reasons to approve of $x$ by approving of $x$. So: If normative testimony gives you reasons for certain attitudes, why is it fishy to form those attitudes in response to normative testimony? The view on offer provides no answer.

This is why the puzzle posed by normative testimony looks harder to solve once we recognize that normative testimony gives us good reasons to believe, act, and form affective attitudes like approval and disapproval. ${ }^{24}$

\footnotetext{
${ }^{24}$ For comments on previous drafts, thanks to Chris Howard, Alex Worsnip, Alex King, Stephanie Leary, Daniel Fogal, Zoe Johnson-King, Guy Fletcher, David Enoch, Sarah McGrath, Errol Lord, Jan Dowell, Pete Graham, and several anonymous referees. I'd also like to thank many more than I can name for helpful conversations about this material, including audiences at the Australasian Association of Philosophy, Sydney University, UNC Chapel Hill, and the University of Madison Wisconsin. And an extra special thanks to Russ Shafer-Landau, to the Marc Sanders Foundation, and to the Prize Committee. If this chapter weren't defending deference to normative experts, I'd be somewhat inclined to question their judgment.
} 


\section{References}

Björnsson, G. and McPherson, T. (2014) 'Moral attitudes for non-cognitivists: Solving the specification problem', Mind 123(489): 1-38.

Broome, J. (2008) 'Reply to Southwood, Kearns and Star, and Cullity', Ethics 119: 96-108.

Brunero, J. (2018) 'Reasons, evidence, and explanations', in D. Star (ed.) Oxford Handbook of Reasons and Normativity. Oxford: Oxford University Press.

Crisp, R. (2014) 'Moral Testimony Pessimism: A Defence', Supplement to the Proceedings of The Aristotelian Society 88: 129-43.

Driver, J. (2006) 'Autonomy and the Asymmetry Problem for Moral Expertise', Philosophical Studies 128(3): 619-44.

Enoch, E. (2014) 'A Defense of Moral Deference', Journal of Philosophy 111(5): 1-30.

Fletcher, G. (2016) 'Moral Testimony: Once More With Feeling', in Russ ShaferLandau (ed.), Oxford Studies in Metaethics vol. 11 Oxford: Oxford University Press.

Gorodeisky, K. (2010) 'A new look at Kant's view of aesthetic testimony', British Journal of Aesthetics 50(1): 53-70.

Groll, D. and Decker, J. (2014) 'Moral Testimony: One of These Things is Just Like the Others', Analytic Philosophy 55(1): 54-74.

Hanson, L. (2018) 'Moral Realism, Aesthetic Realism, and the Asymmetry Claim', Ethics 129(1): 39-69.

Hills, A. (2009) 'Moral Testimony and Moral Epistemology', Ethics 120: 94-127.

Hopkins, R. (2007) 'What is Wrong with Moral Testimony', Philosophy and Phenomenological Research 74: 611-34.

Hopkins, R. (2011) 'How to be a Pessimist about Aesthetic Testimony', Journal of Philosophy 108(3): 138-57.

Johnson King, Z. (2019) 'We can have our buck and pass it, too,' in R. ShaferLandau (ed.), Oxford Studies in Metaethics. Oxford: Oxford University Press.

Lord, E. (2016) 'On the Rational Power of Aesthetic Testimony', British Journal of Aesthetics 56(1).

Lord, E. (2018) 'How to Learn about Aesthetics and Morality Through Acquaintance and Deference', in R. Shafer-Landau (ed.), Oxford Studies in Metaethics. Oxford: Oxford University Press.

Markovits, J. (2012) 'Saints, heroes, sages, and villains', Philosophical Studies, 158: 289-311. 
McBride, M. (2013) 'Kearns and Star on reasons as evidence', Analytic Philosophy 54: 229-36.

McGrath, S. (2009) 'The Puzzle of Pure Moral Deference', Philosophical Perspectives 23: 321-44.

McGrath, S. (2011) 'Skepticism about Moral Expertise as a Puzzle for Moral Realism', Journal of Philosophy 108(3): 11-137.

McKeever, S. and Ridge, M. (2012) 'Elusive reasons' in R. Schafer-Landau (ed.), Oxford Studies in Metaethics volume 7. Oxford: Oxford University Press.

McNaughton, D. and Rawling, R. (2011) 'The making/evidential reason distinction', Analysis 71: 100-2.

Meskin, A. (2004) 'Aesthetic Testimony: What Can We Learn From Others About Beauty and Art?' Philosophy and Phenomenological Research 69(1): 65-91.

Mogensen, A. (2015) 'Moral Testimony Pessimism and the Uncertain Value of Authenticity', Philosophy and Phenomenological Research 95(2): 261-84.

Nickel, P. (2001) 'Moral Testimony and Its Authority', Ethical Theory and Moral Practice 4(3): 253-66.

Reisner, A. and van Weelden, J. (2015) 'Moral Reasons for Moral Beliefs: A Puzzle for Moral Testimony Pessimism', Logos and Episteme 6(4): 429-48.

Roberts, D. (2013) 'Thick Concepts', Philosophy Compass 8: 677-88.

Robson, J. (2012) 'Aesthetic Testimony', Philosophy Compass 7(1): 1-10.

Schroeder, M. (2007) Slaves of the Passions. Oxford: Oxford University Press.

Sliwa, P. (2012) 'In Defense of Moral Testimony', Philosophical Studies 158(2): 175-95.

Speaks, J. (2008) 'Conversational implicature, thought, and communication', Mind and Language 23(1): 487-505.

Whiting, D. (2015) 'The Glass is Half Empty: A New Argument for Pessimism about Aesthetic Testimony', British Journal of Aesthetics 55(1): 91-107.

Wodak, D. (2020) 'Redundant Reasons', The Australasian Journal of Philosophy 98(2): 266-78.

Wollheim, R. (1980) Art and Its Objects. Cambridge: Cambridge University Press.

Zangwill, N. (2013) 'Moral Metaphor and Thick Concepts', in Simon Kirchin (ed.), Thick Concepts. Oxford: Oxford University Press: 197-209. 